\title{
Toluidine Blue Staining Method
}

National Cancer Institute

\section{Source}

National Cancer Institute. Toluidine Blue Staining Method. NCI Thesaurus. Code C92302.

A microscopy staining method that utilizes toluidine blue, a solution composed of

tolonium chloride, to determine the presence of mast cells, lignin, proteoglycans and glycosaminoglycans. 